\title{
Chronic Psychosocial Stress Causes Apical Dendritic Atrophy of Hippocampal CA3 Pyramidal Neurons in Subordinate Tree Shrews
}

\author{
Ana María Magariños, ${ }^{1}$ Bruce S. McEwen, ${ }^{1}$ Gabriele Flügge, ${ }^{2}$ and Eberhard Fuchs ${ }^{2}$ \\ 1The Rockefeller University, New York, New York 10021, and '2German Primate Center, 37077 Göttingen, Germany
}

We have shown previously that repeated laboratory restraint stress or daily corticosterone administration affects the structure of CA3 hippocampal neurons in rats. In the present study, we investigated the effect of repeated daily psychosocial stress on the structure of hippocampal CA3 pyramidal neurons in male tree shrews (Tupaia belangeri). Male tree shrews develop social hierarchies in which subordinates show characteristic changes in physiological and behavioral parameters when confronted with a dominant. In the present experiments, subordinate animals lost body weight soon after starting the daily social conflict, and urinary excretion of cortisol was elevated throughout the experiment as compared with the control period. Golgi-impregnated brain tissue from subordinates exposed to $28 \mathrm{~d}(1 \mathrm{hr} / \mathrm{d})$ of social confrontations was compared with that from control nonstressed animals. The apical dendrites of the CA3 pyramidal cells from subordinates had a decreased number of branch points and total dendritic length as compared with controls. No differences were observed in apical dendritic spine density or in the basal dendritic tree morphology. The stress-induced CA3 apical dendritic atrophy in subordinates was prevented by administering daily oral doses of the antiepileptic drug phenytoin (Dilantin, Sigma, St. Louis, MO) $(200 \mathrm{mg} / \mathrm{kg})$, which interferes with excitatory amino acid (EAA) action. These results suggest that the naturalistic stressor psychosocial stress induces specific structural changes in hippocampal neurons of subordinate male tree shrews. These changes, like those in the rat after glucocorticoid treatment or restraint stress, probably are mediated by activation of the hypothalamo-pituitary-adrenal-axis acting in concert with endogenous EAAs from mossy fiber input.

Key words: Golgi impregnation; hippocampus; Tupaia; pyramidal neuron; excitatory amino acids; phenytoin; glucocorticoids
Repeated restraint stress or a combination of daily stressors in rats induce atrophy of hippocampal CA3 pyramidal neurons (Walanabe et al., 1992c; Magariños and McEwen, 1995a). This atrophy is mimicked by daily treatment with corticosterone (Woolley et al., 1990), indicating that elevated circulating adrenal steroids secreted during stress may be involved in triggering the morphological alterations. Indeed, the pharmacological blockade of the corticosterone stress response prevented the hippocampal atrophy (Magariños and McEwen, 1995b). However, glucocorticoids have been shown to act synergistically with excitatory amino acids (EAAs) (Krugers et al., 1993; Lowy et al., 1993), and mossy fibers originating from granular neurons of the dentate gyrus provide a strong input of EAAs into the hippocampal CA3 region (Clairbone et al., 1986). Thus, daily treatment of rats with phenytoin, an antiepileptic agent that interferes with EAA release and action, blocked both corticosterone- and stress-induced CA3 pyramidal neurons atrophy (Watanabe et al., 1992a). The pharmacological blockade of central NMDA receptors also prevented the hippocampal atrophy (Magariños and McEwen, 1995b). Taken logether, these results suggest a synergy between glucocorticoids and EAAs in stress-induced atrophy of CA3 pyramidal neurons.

Most preclinical studies relating stress and hippocampal morphology derived from studies in rodents. Only a limited number of

\footnotetext{
Received Oct. 11, 1995; revised Feb. 29, 1996; accepted March 4, 1996.

This research was supported by National Institutes of Health Grant MH41256 and The Health Foundation, New York, to B.Mc. We appreciate the advice of Dr. Barry Smith, The Health Foundation, New York, regarding phenytoin, and the help of Dr. Bruce Schneider (Vet Research) for measuring phenytoin in the tree shrew plasma. We express our thanks to Andreas Heutz for his excellent technical assistance.

Correspondence should be addressed to Dr. Ana María Magariños, The Rockefeller University, 1230 York Avenue, New York, NY 10021.
}

Copyright (C) 1996 Society for Neuroscience $0270-6474 / 96 / 163534-07 \$ 05.00 / 0$ investigations examined the influence of stress or long-term glucocorticoid treatment on hippocampal neurons in other species (Uno et al., 1994). To better understand the effects of stressful psychological situations in a nonrodent mammalian species, we used the psychosocial stress paradigm in male tree shrews (Tupaia belangeri). This species is regarded phylogenetically as an intermediate between insectivores and primates (Martin, 1990) and proved to be a suitable model to study the neuro-behavioral consequences of the naturalistic psychosocial stressor (Flügge et al., 1992; Jöhren et al., 1994; Flügge, 1995; Fuchs et al., 1995). Adult male tree shrews display an intense territoriality that can be used to establish a naturally occurring challenge situation under experimental control in the laboratory. Coexistence of two males in one cage leads to a stable dominant-subordinate relationship, with subordinates showing distinct stress-induced behavioral and physiological alterations from the moment of subjugation onward. Subordinates withdraw from the field of vision of the dominant, become hypoactive, alter their sleeping pattern (Aue, 1989), and show increased adrenal hormone levels and decreased gonadal activity (Fischer et al., 1985; Fuchs et al., 1993). The characteristic reduction of body weight in subordinates is related to a diminished food and water intake and to an elevated metabolism (Aue, 1989; Jöhren et al., 1991). After chronic psychosocial stress, central $\alpha_{2}$-adrenoceptors are affected in areas involved primarily in the regulation of autonomic functions (Flügge et al., 1992), and hippocampal glucocorticoid receptors are downregulated while corticotropin-releasing hormone receptors are up- or downregulated in a region-specific manner (Fuchs and Flügge, 1995). Using this well-characterized tree shrew stress paradigm, we investigated the impact of psychosocial stress, as well as cotreatment with the antiepileptic phenytoin, on the morphology of Golgi-impregnated 
hippocampal CA3 pyramidal neurons in subordinate tree shrews as compared with control nonstressed animals. Dominant animals were only used to induce psychosocial stress in subordinates. All animals were tested for daily urinary cortisol excretion and body weight.

\section{MATERIALS AND METHODS}

The experiments were conducted with adult male tree shrews (Tupaia belangeri) from the breeding colony at the German Primate Center (Göttingen, Germany). All animal experimentation was conducted in accordance with the National Institutes of Health Guide for the Care and Use of Laboratory Animals and were approved by the Government of Lower Saxony, Germany. The animals were housed individually on a regular dark/light cycle with artificial illumination from 8 A.M. to 8 P.M. in air-conditioned rooms (for details, see Fuchs and Schumacher, 1990).

Experimental procedures. During a $10 \mathrm{~d}$ control period, the body weights of five subordinate, five dominant, and five control male tree shrews were recorded, and the basal activity of the pituitary-adrenocortical-axis was determined by measuring cortisol in the morning urine, which was collected after a light massage of the hypogastrium daily between 7:45 A.M. and 8.00 A.M. The time between initially perturbing the animals and the collection of urine was always less than $2 \mathrm{~min}$.

The experimental induction of psychosocial conflict was carried out as follows. After the control period, the opaque partition between the neighboring cages of two males unknown to one another was removed. This resulted in an active competition for control over the enlarged territory. After establishment of a stable dominant-subordinate relationship, the two males were separated by a transparenl wire mesh. Under these conditions, the subordinate animal reduced its sphere of action in the cage and avoided situations that could evoke attacks from the dominant animal. 'This period of psychosocial conflict lasted for $28 \mathrm{~d}$. During this time, the wire mesh was removed every day for $1 \mathrm{hr}$ between 9.00 A.M. and 11.00 A.M. Urine samples were collected every morning between 7:45 A.M. and 8.00 A.M., and the animals were weighed as described above. The time between initially perturbing the animals and the collection of urine, again, was less than $2 \mathrm{~min}$, and there were no differences in time in relation to social position. Control animals lived in separate quarters elsewhere in the animal facility. From these animals, morning urine samples were collected and body weight was recorded daily as described for the experimental animals.

Pharmacological treatment. In a second experiment, subordinate animals $(n=6)$ were administered a daily oral dose of phenytoin (Sigma, St. Louis, MO) each morning ( $200 \mathrm{mg} / \mathrm{kg}$, diluted in water). For this purpose, each animal was grabbed gently, and a bulb-headed probe was inserted into its mouth, slid over the tongue, and then slipped carefully down the esophagus. With this procedure, the dose was swallowed completely and the stress caused to the animals was minimized, because control tree shrews $(n=5)$ that received water in the same way that phenytoin was given to subordinates showed no stress-induced urinary cortisol excretion. The rest of the psychosocial confrontation experiment was conducted as described above. Several dosages of phenytoin, ranging from 5 to 200 $\mathrm{mg} / \mathrm{kg}$, were tried in pilot experiments and the $200 \mathrm{mg} / \mathrm{kg}$ dose was sclectcd, becausc it yicldcd averagc plasma lcvels of $20 \mu \mathrm{g}$ of phenytoin per $\mathrm{ml}$. This titer is within the concentration range described in the literature to be effective as a neuroprotectant (Yaari et al., 1986; Taft et al., 1989). Phenytoin levels were measured in plasma samples withdrawn $3 \mathrm{hr}$ after its administration using an Automated Direct Reading of Fluorescence Polarization Immunoassay (Abbot Diagnostics) (Jolley, 1981).

Golgi impregnation and analysis. At the end of the confrontation period, subordinate and control animals were killed between 8:00 A.M. and 9:00 A.M., and care was taken to exclude nonspecific stress effects. They were anesthetized deeply with a Ketamine/Xylazine mixture and perfused transcardially with $100 \mathrm{ml}$ of a commercial blood substitute (Onkovertin, Braun, Melsungen, Germany) for $3 \mathrm{~min}$, followed by $150 \mathrm{ml}$ of $4 \%$ paraformaldehyde in $0.1 \mathrm{M}$ phosphate buffer. Brains were post-fixed overnight in the perfusate at $4^{\circ} \mathrm{C}$. Sections, $100 \mu \mathrm{m}$ thick, were cut with a vibratome into a bath of $3 \%$ potassium dichromate in distilled water and then processed according to a modified version of the single-section Golgi-impregnation procedure (Gabbot and Somogy, 1984). Briefly, the brain sections were incubated overnight in $3 \%$ potassium dichromate dissolved in distilled water, then rinsed in distilled water and mounted on plain slides. A coverslip was glued over the sections at the four corners. These slide assemblies were incubated overnight in $1.5 \%$ silver nitrate, in the dark. The following day, the slide assemblies were dismantled and the tissue sections rinsed in distilled water, dehydrated, and defatted with a graded series of ethanol, followed by Histoclear (Americlear). Finally, the sections were mounted on gelatin-coated slides and coverslipped with Permount (Fisher Scientific, Orangeburg, NY). Slides containing brain sections were coded before quantitative analysis; the code was not broken until the analysis was complete. To be selected for analysis, Golgiimpregnated neurons had to possess the following characteristics: (1) location within the CA3 subregion of the hippocampus; (2) dark and consistent impregnation throughout the extent of all of the dendrites; (3) relative isolation from neighboring impregnated cells, which could interfere with the analysis; and (4) somata located in the middle third section to minimize the number of truncated branches. For each brain, six to eight pyramidal cells from area CA3 were selected. Because three subtypes of CA3 ncurons with different apical branching patterns can be impregnated (Fitch et al., 1989), the same proportion of neuronal subclasses was included for each brain. Each neuron selected was traced at $400 \times$ magnification using a light microscope with a camera lucida drawing tube attachment. From these drawings, the number of dendritic branch (bifurcation) points within a $100 \mu \mathrm{m}$ section of each dendritic tree was determined for each neuron selected. In addition, the length of the dendrites present in a $100 \mu \mathrm{m}$ section was determined for each dendritic tree using a Zeiss Interactive Digitizing Analysis System. For each pyramidal cell, spine density analysis was performed at the stratum lacunosum moleculare level of the CA3 field from the most lateral tertiary dendrite on the apical tree. Camera lucida tracings $(1250 \times$ ) were obtained from selective dendritic segments that remained in the plane of focus and had a length between 30 and $70 \mu \mathrm{m}$. All visible spines along the selected dendritic segment were measured from the camera lucida drawings with the Zeiss Interactive Digitizing System, and spine density values were expressed as number of spines $/ 10 \mu \mathrm{m}$ dendrite. Six CA3 pyramidal cells from each animal were chosen for the study. For each neuron, six dendritic branches were analyzed. For each variable (branch points, length, and spine density) and for each subject, mean \pm SEM was determined, and the resulting values were analyzed statistically as indicated below.

Analysis of urine samples. Urinary cortisol was measured by a scintillation proximity radioimmunoassay (Udenfriend et al., 1985) using antirabbit cortisol antiserum (Paesel-Lorei, Frankfurt, Germany), anti-rabbit IGG-coated fluomicrospheres (scintillation proximity assay anti-rabbit reagent type I) (Amersham, Braunschweig, Germany), and $\left[{ }^{3} \mathrm{H}\right]$ cortisol (Amersham) as (racer. To correct for physiological dilutions, the resulting concentrations were related to creatinine concentrations, which were determined with a Beckman Creatinine Analyzer 2.

Statistical analysis. Number of branch points, total dendritic length, and spine density averages for each subject were analyzed with Student's $t$ test. Body weight and cortisol data analysis were assessed by the KruskalWallis one-way ANOVA, followed by the Mann-Whitney $U$ test. A probability level of $p<0.05$ was used to determine statistical significance.

\section{RESULTS}

\section{Psychosocial stress effect on CA3 pyramidal neuron structure}

After $28 \mathrm{~d}$ of daily social conflict, subordinate animals showed a significant decrease in the number of apical branch points $(p<$ $0.01)$ and total apical dendritic length $(p<0.05)$ in hippocampal CA3 pyramidal neurons as compared with controls (Fig. 1). All neuronal subtypes showed atrophy of their apical trees, but no detectable changes were observed in the morphology of the basal dendritic trees of the same neurons, regardless of the subclass considered. Figure 2 depicts representative camera lucida drawings of CA3 neurons for control and subordinate tree shrews. We also analyzed the apical dendritic spine density of $\mathrm{CA} 3$ neurons, and no differences were apparent between control and subordinate animals after $28 \mathrm{~d}$ of psychological stress $(21.0 \pm 1.5$ and 21.5 \pm 1.8 spines $/ 10 \mu \mathrm{m}$, respectively). The social confrontation did not affect either the dendritic arborizations of the principal neurons in areas CA1 and CA2 or the dentate gyrus (data not shown). 


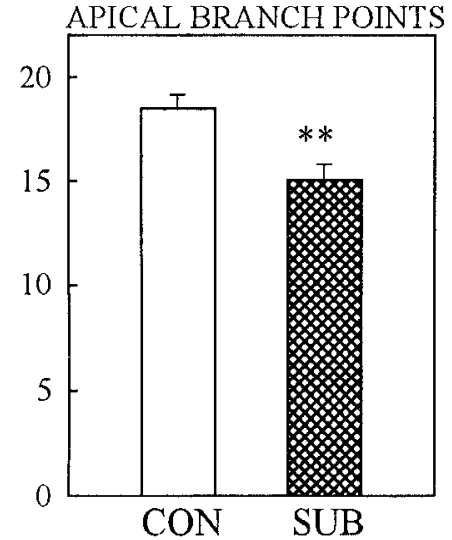

TOTAL APICAL LENGTH
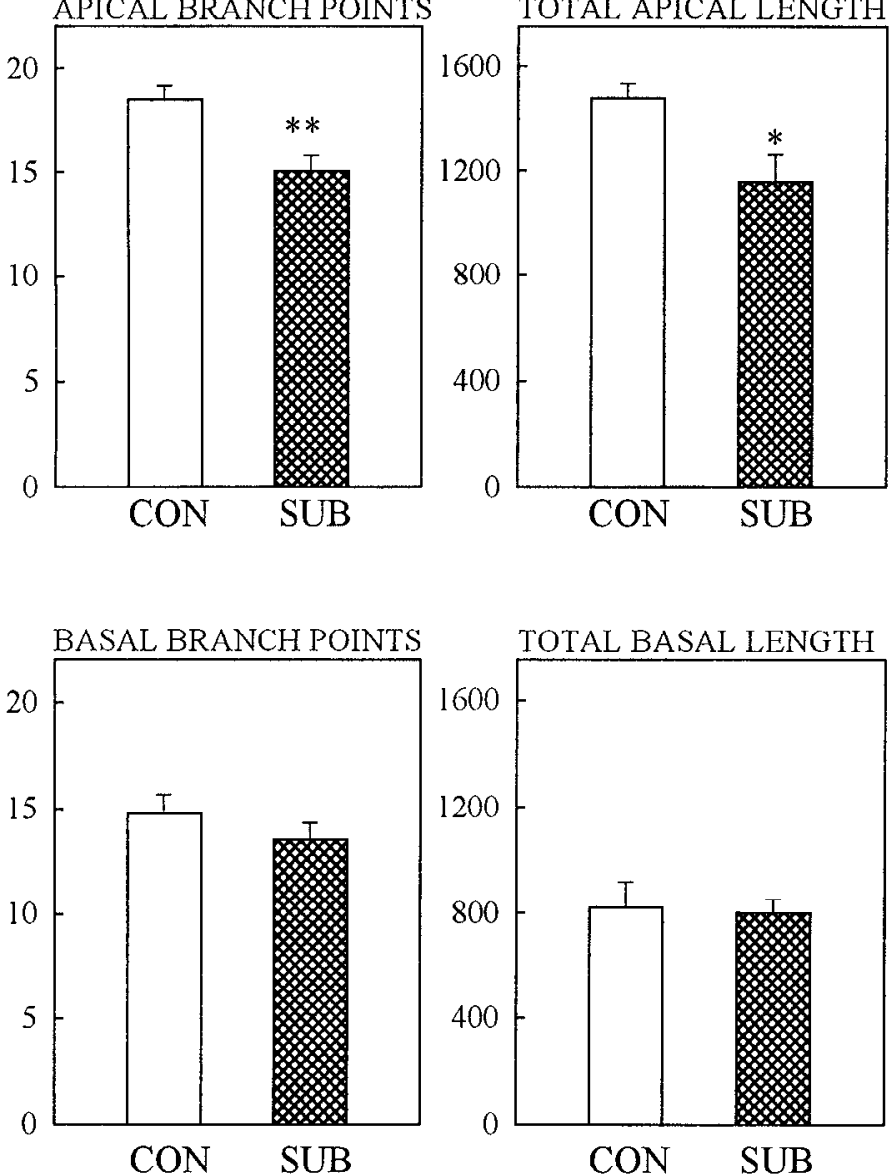

Figure 1. Effect of $28 \mathrm{~d}$ of psychosocial stress on dendritic morphology of CA3 pyramidal neurons is shown for apical and basal dendrites. Note that psychosocial stress reduces the number of apical branch points in subordinates $(S U B)$ as compared with controls $(C O N)$. Bars represent the mean $\pm \mathrm{SEM}$; double asterisk indicates $p<0.01$, and asterisk indicates $p<0.05$ as compared with controls (Student's $t$ test).

\section{Psychosocial stress and phenytoin treatment effect on CA3 pyramidal neuron structure}

Because of our previous data showing that phenytoin blocks both stress- and corticosterone-induced atrophy of $\mathrm{CA} 3$ dendrites in rats (Watanabe et al., 1992a), we used phenytoin in tree shrews in an attempt to block psychosocial stress-induced atrophy. Administration of a $200 \mathrm{mg} / \mathrm{kg}$ oral dose of phenytoin for $28 \mathrm{~d}$ prevented the psychosocial stress-induced apical atrophy of CA3 hippocampal neurons in subordinate trec shrews. Figure 3 shows that control animals had a similar number of branch points and total dendritic length compared with subordinate animals treated with phenytoin. It is important to note that the different values for control groups in Figures 1 and 3 are attributable to the fact that different proportions of pyramidal neuron subtypes were impregnated in the two experiments. Whereas the basal trees show a similar degree of arborization complexity, regardless of the neuronal subtype considered, the apical trees vary according to the subclass examined. In the first experiment, each subject contributed with $20 \%$ of long-shaft neurons, $45 \%$ of short-shaft neurons, and $35 \%$ of two main-shaft neurons to the final average. In the second experiment, the Golgi staining favored a larger number of long-shaft neurons, and each brain contributed with $38 \%$ of longshaft neurons, $50 \%$ of short shaft neurons, and $12 \%$ of two main-shaft neurons to the final average. In other words, in the second experiment, a larger proportion of neurons with poorer apical dendritic trees (long-shaft neurons) and a smaller proportion of neurons with richer apical arborizations (two main-shaft neurons) are reflected in the lower final averages (Fig. 2).

\section{Urinary parameters and body weight}

In subordinate animals, the hypothalamo-pituitary-adrenal (HPA)-axis became chronically activated as indicated by the elevation of urinary cortisol throughout the confrontation period (days 10-38) (Fig. 4) $(p<0.01$, Kruskal-Wallis one-way ANOVA, followed by the Mann-Whitney $U$ test). The intensity of psychosocial stress in subordinates also was indicated by a significant reduction of their body weight from the initiation of social conflict onward (Fig. 4) $(p<0.01$, Kruskal-Wallis one-way ANOVA, followed by the Mann-Whitney $U$-test). Phenytoin treatment did not affect the stress-induced urinary cortisol of subordinates (Fig. 5). However, body weight reduction in phenytoin-treated subordinates during the psychosocial stress period was less pronounced than in pharmacologically untreated subordinatcs (Figs. 4, 5). Control animals ( $\mathrm{kcpt}$ in a scparatc room and not subjected to stress) showed no stimulation of HPA-axis activity, and their body weights remained constant during the entire experimental period (Figs. 4, 5). In the first social confrontation, dominant animals experienced a transient body weight loss at the beginning of the psychosocial conflict period, and cortisol urinary excretion remained within control levels except for days 34-36, when they were slightly increased (Fig. 4). When confronted with phenytoin-treated subordinates, dominant
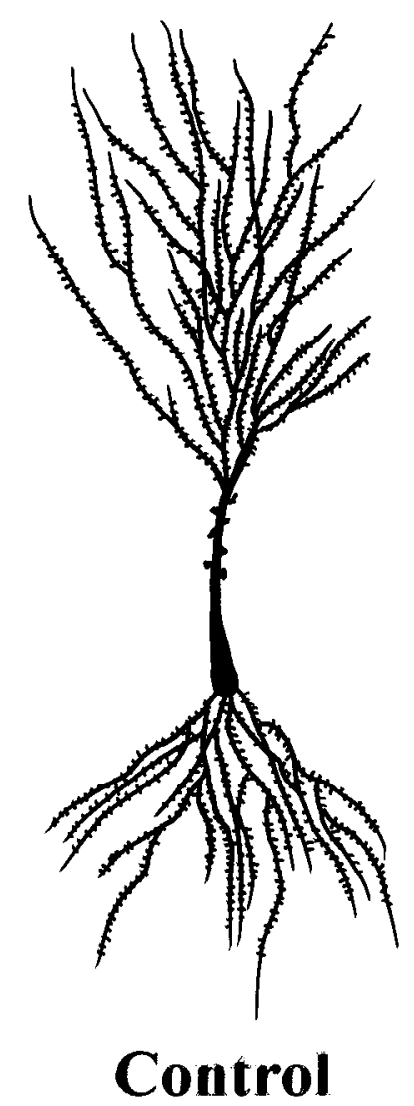
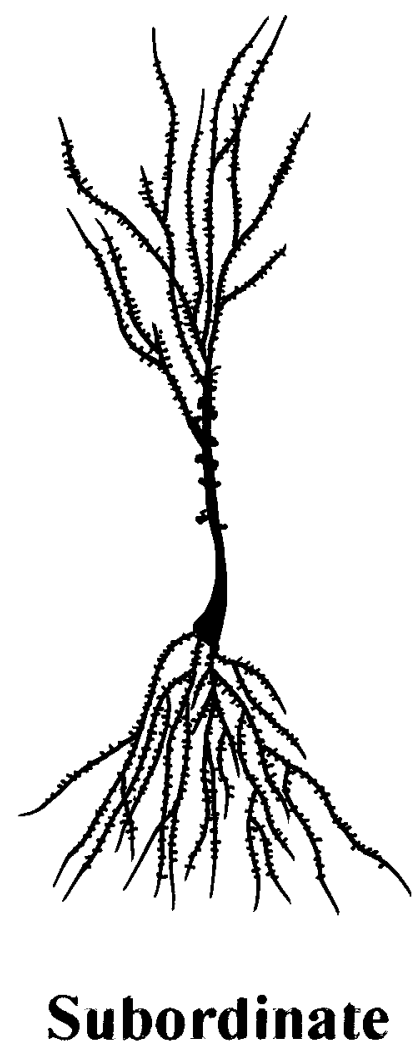

Figure 2. Camera lucida drawings of representative Golgi-impregnated CA3 pyramidal neurons from control (not subjected to stress) and subordinate tree shrews (after $28 \mathrm{~d}$ of psychosocial stress). Notice the decreased branching pattern in the subordinate apical dendritic tree as compared with the control. 

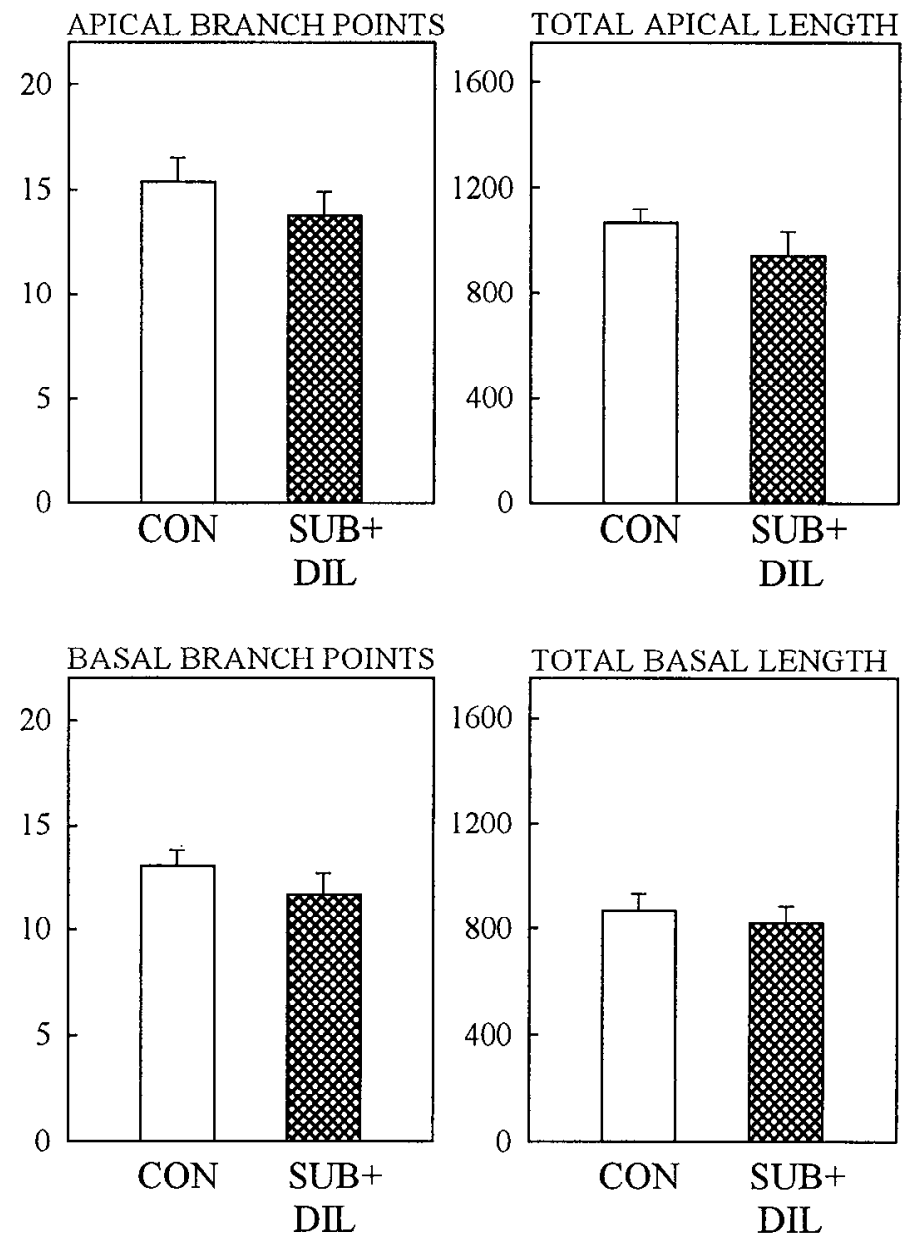

Figure 3. Daily oral administration of phenytoin $(D I L, 200 \mathrm{mg} / \mathrm{kg})$ to subordinate animals ( $S U B$ ) during the $28 \mathrm{~d}$ stress period prevented the occurrence of the CA3 apical dendritic atrophy. Control animals (CON) showed a number of apical dendritic branch points similar to that for subordinates treated with phenytoin. No statistical differences were found in apical dendritic length as well. Bars represent the mean I SEM.

animals did not lose weight, but their cortisol urinary excretion increased slightly during the conflict period, although not as prominently as in subordinates (Fig. 5).

\section{DISCUSSION}

Subordination through psychosocial encounters is an effective stressor, and clear bio-behavioral indices differentiate subordinate from dominant tree shrews (Aue, 1989). In line with these data, the present study revealed several distinctive physiological characteristics of subordinate animals, namely, a rapid and consistent weight loss and an increased and nonhabituated urinary cortisol excretion that is indicative of a prolonged activation of the HPA-axis.

After daily psychosocial confrontation, we observed a stressinduced apical dendritic atrophy of hippocampal CA3 pyramidal cells in the subordinate tree shrews as compared with nonchallenged control animals. All CA3 neuron subtypes of subordinates showed both a lower number of apical dendritic branch points and a smaller apical dendritic length after $28 \mathrm{~d}$ of psychosocial stress as compared with controls. Thus, pyramidal neurons from subordinate animals appear to retract their dendrites, a change that might have an impact on the total number of dendritic synapses. However, the spine density of CA3 apical dendrites of subordi- nate tree shrews was not altered after the confrontation period. Because we did not measure the total number of apical dendritic spines, additional studies should elucidate whether psychosocial stress affects the total number of pre- and postsynaptic elements. Psychosocial stress also is known to cause other morphological alterations within the hippocampus of tree shrews: light microscopic analysis of Nissl-stained hippocampal sections revealed an increased staining intensity of the nucleoplasm in CA1 and CA3 pyramidal neurons of subordinate tree shrews (Fuchs et al., 1995). Considering the present results, the modified appearance of the nucleus may reflect altered genomic activity that could underlie the atrophic changes in the dendrites.

In contrast to subordinates, dominant male tree shrews revealed only a transient increase in cortisol excretion during the late phase of the confrontation period in the first experiment. Transient increases in cortisol excretion can be attributed to sometimes uncontrollable stimuli (e.g., noise in the animal facility). In the second experiment, the increase of urinary cortisol levels in dominants may result from the fact that the data were calculated as percentage of the control period and, in this particular experiment, control levels were somewhat lower than usual. Although the alterations in dominant urinary cortisol levels are minimal in comparison to the changes observed in subordinates, it cannot be excluded that dominants also experienced some stress during the social confrontation, despite the fact that no noticeable behavioral and physiological alterations were described before (Aue, 1989; Jöhren et al., 1991; Fuchs et al., 1993). However, future studies will be needed to establish the possible degree of stress-induced hippocampal changes in the dominants. For the present study, we focused on those tree shrews that obviously were undergoing pronounced and chronic stressful cxpcricnces as indicated by the changes in physiological parameters as well as by the characteristic subordination behavior.

As in the rat and other mammalian species, including human beings, the hippocampus of tree shrews contains high levels of receptors for adrenocorticoids as shown by in vivo autoradiography (Flügge et al., 1988). A recent in situ hybridization study demonstrated that the density of mRNA encoding the glucocorticoid receptor was decreased in the hippocampal formation of subordinate tree shrews (Jöhren et al., 1994). Glucocorticoids have a permissive role and act synergistically with EAAs in producing neuronal death in cell culture and in vivo (Sapolsky, 1992). The major excitatory input to the CA3 pyramidal cells is the mossy fiber projection from the granule neurons from the dentate gyrus (Clairbone et al., 1986). In addition, the possibility of an excitatory input from commissural or associational afferents has to be considered (Bayer, 1985). Furthermorc, clcctrical stimulation of the perforant path leads to granule neuron seizure activity, which, in turn, induces CA3 dendritic damage and neuronal loss (Sloviter, 1993). Such damage is potentiated by glucocorticoids and appears to involve endogenous glucocorticoid and EAA receptordependent processes (Sapolsky, 1992). Moreover, a significant increase of extracellular hippocampal glutamate concentration was reported after acute restraint stress (Moghaddam, 1993), and, in another experiment using microdialysis probes implanted into the hippocampus, adrenalectomy suppressed the stress-induced release of glutamate completely (Lowy et al., 1993). Thus, it is possible that glutamate release is an important component of stress-induced processes leading to atrophy of $\mathrm{CA} 3$ neurons. Finally, as noted above, phenytoin, an antiepileptic drug that inhibits EAA release and blocks its activation of T-type calcium channels, prevented both the corticosterone- and the stress- 


\section{CORTISOL}
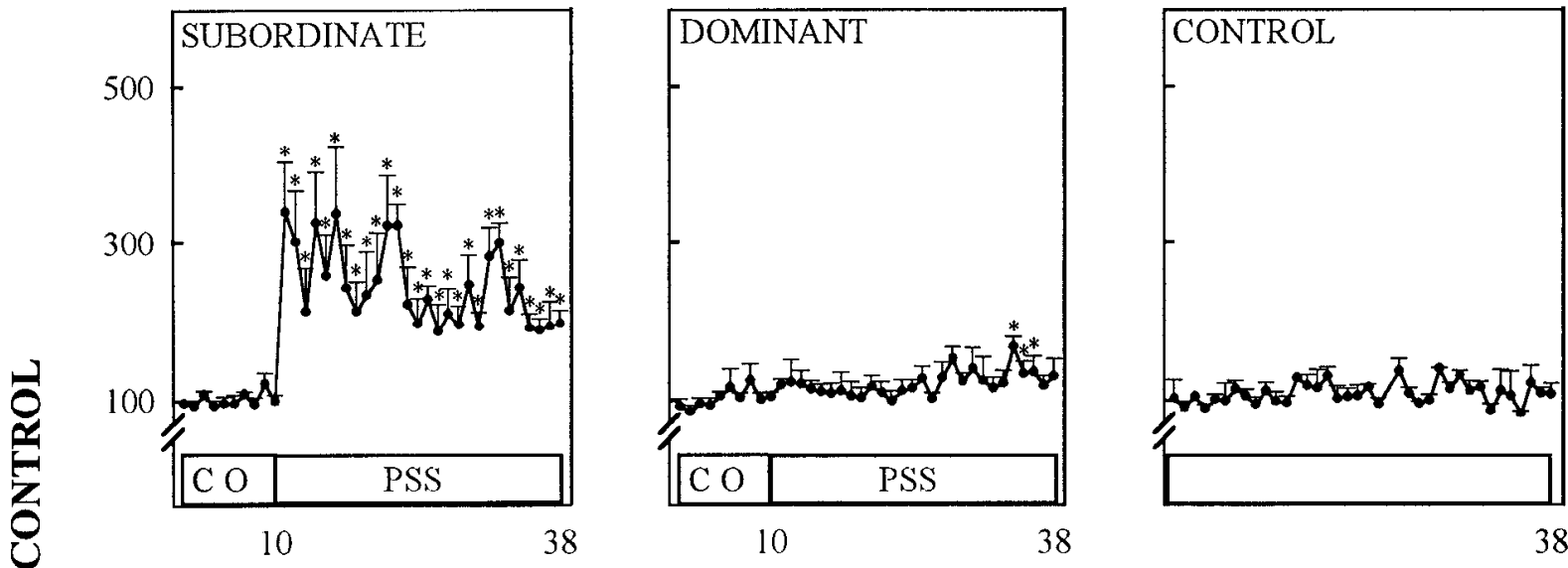

38

\section{BODY WEIGHT}
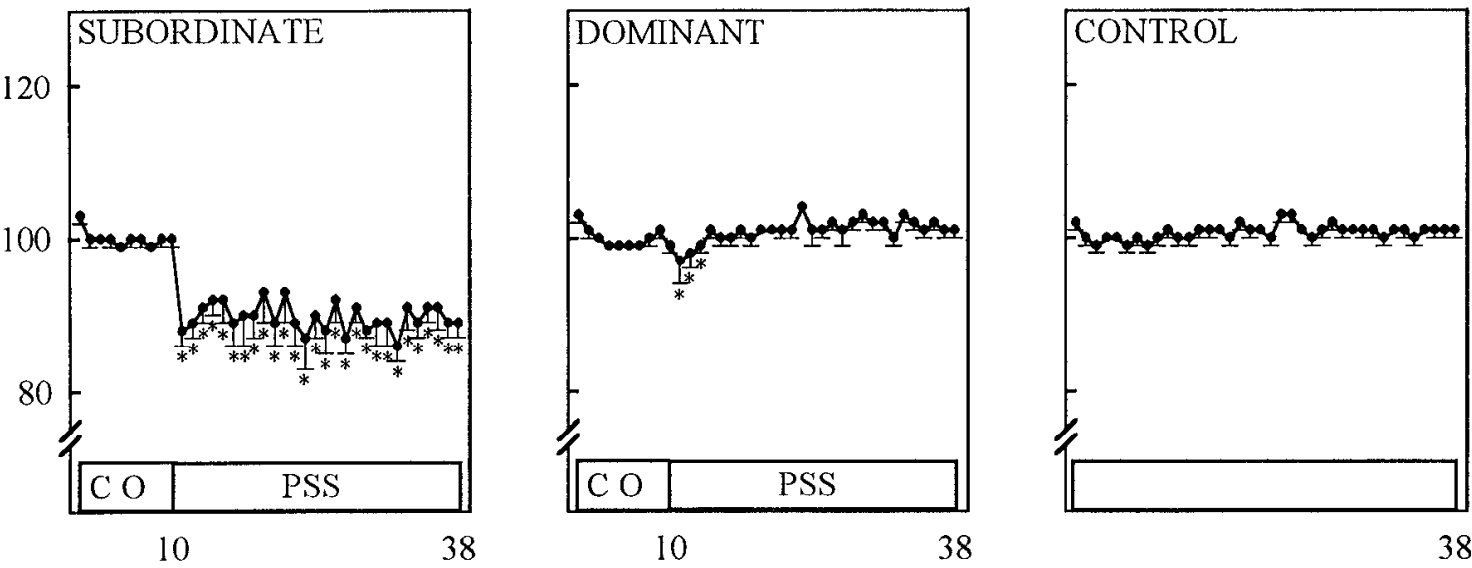

DAYS

Figure 4. Effect of psychosocial stress on cortisol in morning urine and relative body weight during a control period $(\mathrm{CO})$ and a subsequent period of psychosocial stress (PSS). Control animals were handled like subordinates and dominants, but were not subjected to psychosocial stress. Data are given as percentage of mean values during the control period (mean \pm SEM).

induced atrophy of hippocampal CA3c apical dendrites in rats (Watanabe et al., 1992a). And, indeed, as shown in the present study, whereas glucocorticoid levels are clearly elevated in subordinate tree shrews and are likely to contribute to the atrophy in the hippocampus as they do in the rat (Magariños and McEwen, 1995b), daily treatment of subordinate tree shrews with phenytoin prevented the psychosocial stress-induced dendritic atrophy. Although phenytoin's mechanisms of action appear to be complex and to involve many components (De Lorenzo, 1989), the present results imply that EAAs may be involved, an inference that is supported by the fact that NMDA receptor blockade prevented stress-induced atrophy of apical dendrites of CA3 neurons in the rat hippocampus (Magariños and McEwen, 1995b).

Besides adrenal steroids and EAAs, potentially important connections exist between EAAs and serotonin (5-HT). As discussed above, EAAs have the ability to promote dendritic atrophy by mechanisms involving NMDA receptors (Magariños and McEwen, 1995b). Serotonin inhibits neurite outgrowth and synaptogenesis (Haydon et al., 1985) and has been reported to facilitate neuronal responses to EAAs (Nedergaard et al., 1987). Hippocampal serotonin concentrations are increased during psycho- social conflict in rats (Blanchard et al., 1993) and also are increased in the brains of subordinate tree shrews, as indicated by a downregulation of 5- $\mathrm{HT}_{1 \mathrm{~A}}$ receptors (Flügge, 1995). Thus, a pharmacolugical agent that reduces serotonin levels during stress might prevent stress-induced atrophy of hippocampal CA3 dendrites. Indeed, tianeptine, an atypical tricyclic antidepressant that facilitates serotonin uptake, blocked the corticosterone- and stress-induced dendritic atrophy in rats (Watanabe et al., 1992b). Future experiments will address the possible involvement of 5-HT in the morphological effects of psychosocial stress in the tree shrew.

In view of the role of the hippocampus in spatial information processing and episodic learning and memory (Squire, 1983; Eichenbaum and Otto, 1992), the functional significance and the behavioral consequences of the stress-induced atrophy are beginning to receive increasing attention (McEwen and Sapolsky, 1995). One question is whether this atrophy is the beginning of irreversible hippocampal damage or a protection mechanism to prevent neuronal loss. It is interesting to note that in rats, the stress-induced atrophy is a reversible phenomenon within 10 to 20 $\mathrm{d}$ after the termination of daily stress (A. M. Magariños and B. 


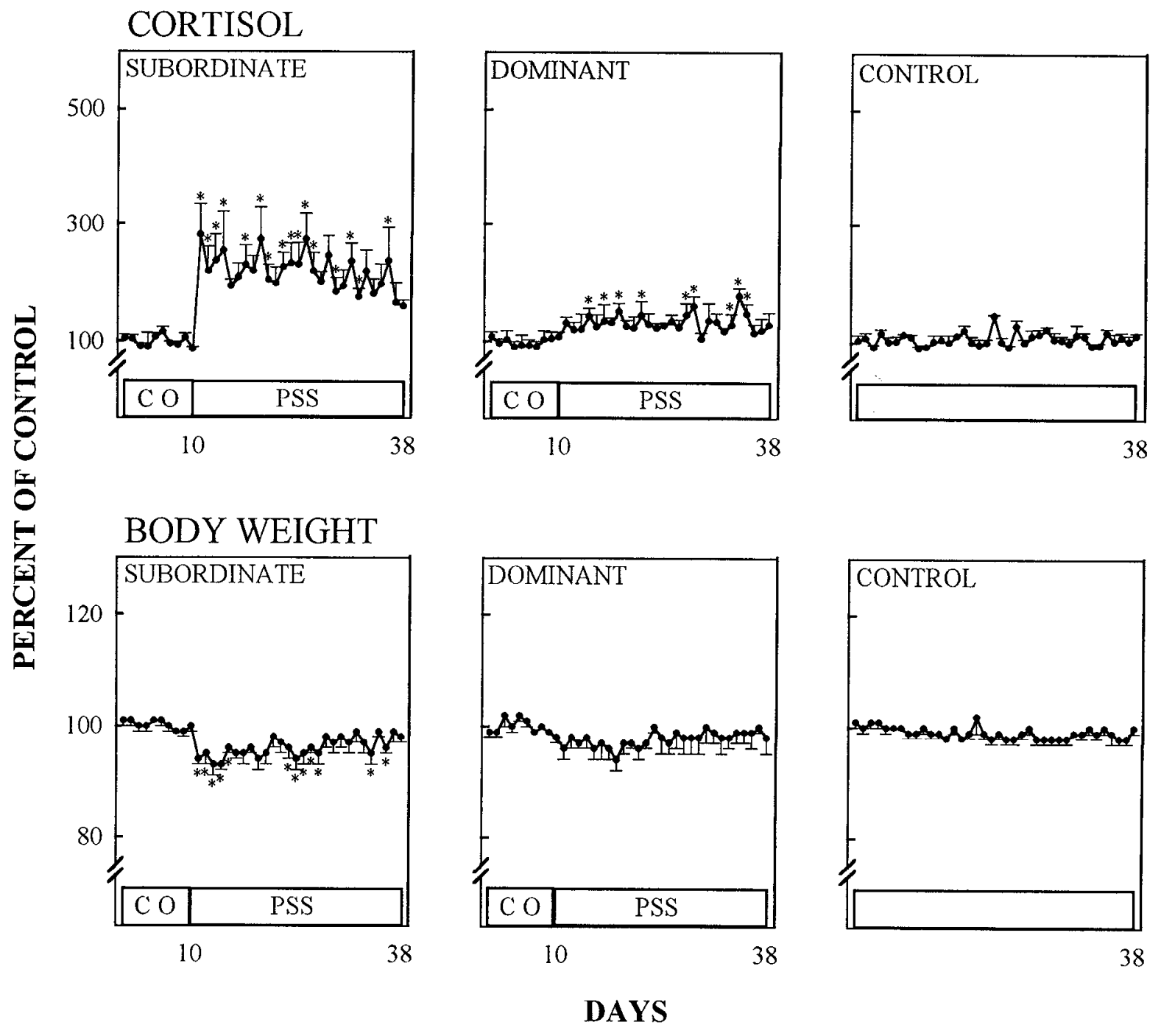

Figure 5. Effect of phenytoin treatment on morning urine cortisol levels and body weight during a control period $(\mathrm{CO})$ and a subsequent period of psychosocial stress (PSS). Control animals were handled and treated with phenytoin as subordinates, but were not subjected to psychosocial stress. Data are given as percentage of mean values during the control period (mean $\pm S E M$ ).

McEwen, unpublished observations). Thus, it is possible that by reducing the number of contacts with the excitatory inputs from the mossy fibers and other synaptic inputs, the apical dendritic atrophy might protect CA3 pyramidal neurons from destruction. Likewise, the reduction of glucocorticoid receptor mRNA levels in tree shrew hippocampus by psychosocial stress (Jöhren et al., 1994) might downregulate one of the principal mechanisms by which neuronal destruction is produced.

Yet, protective or not, the dendritic atrophy found in the tree shrew and the rat may contribute to cognitive impairment as has bcen demonstrated in rats after $21 \mathrm{~d}$ of daily restraint stress (Luine et al., 1993). This impairment was reversible and could be blocked by phenytoin and tianeptine, the same agents that blocked stress-induced atrophy of CA3 pyramidal neurons (Luine et al., 1993). In primates, prenatal dexamethasone treatment of Rhesus monkeys resulted in later life in a significantly elevated cortisol level and an $\sim 30 \%$ reduction of hippocampal size and volume (Uno et al., 1994). Because the hippocampus is highly vulnerable to various challenges such as ischemia, epilepsy, and aging (Sapolsky, 1992; McEwen et al., 1993), additional studies should find out whether similar neuronal effects also occur in the human brain. Initial evidence suggests that the underlying cellular mechanisms in humans and experimental animals may be comparable in that in Cushing's disease patients and normal elderly subjects, reduced hippocampal volume is correlated with elevated plasma cortisol levels and with deficits in delayed recall of word lists (Starkman et al., 1992; Golumb et al., 1994; Convit ct al., 1995). Furthermore, reduced hippocampal volume was suggested to be a risk factor for later dementia (Convit et al., 1995).

In conclusion, the present experiments establish that a naturalistic psychosocial stressor in a nonrodent mammal, which is situated phylogenetically between insectivores and primates, produces morphological changes in the $\mathrm{CA} 3$ region of the hippocampal formation of the mature brain, Inuch as was demonstrated in the rat brain after $21 \mathrm{~d}$ of chronic corticosterone treatment or repeated laboratory stresses (Watanabe et al., 1992c; Magariños and McEwen, 1995a,b). The present study also supports a crucial role of glucocorticoids and EAAs (Magariños and McEwen, 1995b; Moghaddam, 1993) in triggering dendritic atrophy and points out the need to investigate mechanisms in primate and human brains by which cortisol elevation and persistent stress may lead to hippocampal morphological changes and cognitive impairment. 


\section{REFERENCES}

Aue D (1989) Konfrontationen zwischen männlichen Spitzhörnchen (Tupaia belangeri): konsequenzen der Sozialkontakte für Verhalten und Physiologie sowie der Einfluss individueller und äusserer Faktoren auf die Dominanzentscheidung. Göttingen: Thesis.

Bayer SA (1985) Hippocampal region. In: The rat nervous system (Paxinos G, ed), pp 335-352. New York: Academic.

Blanchard DC, Sakai RR, McEwen BS, Weiss SM, Blanchard RJ (1993) Subordination stress: behavioral, brain and neuroendocrine corrclations. Behav Brain Res 58:113-121.

Clairbone BJ, Amaral DG, Cowan WH (1986) A light microscopic analysis of the mossy fibres of the rat dentate gyrus. J Comp Neurol 246:435-458.

Convit A, de Leon MJ, Tarshish CY, de Santi S, Kluger A, Rusinek H, George AE (1995) Hippocampal volume losses in minimally impaired elderly. Lancet 345:266.

De Lorenzo RJ (1989) Phenytoin: mechanism of action. In: Antiepileptic drugs, 3rd Ed (Levy R, Mattson R, Meldrum B, Penry JK, Dreifus FE, eds), pp 143-158. New York: Raven.

Eichenbaum H, Otto T (1992) The hippocampus: what does it do? Behav Neural Biol 57:2-36.

Fischer HD, Heinzeller T, Raab A (1985) Gonadal responses to psychosocial stress in male tree shrews (Tupaia belangeri): morphometry of testis, epididymis and prostate. Andrologia 17:262-275.

Fitch JM, Juraska JM, Washington LW (1989) The dendritic morphology of pyramidal neurons in the rat hippocampal CA3 area. I. Cell types. Brain Res 479:105-114.

Flügge $\mathrm{G}$ (1995) Dynamics of $5 \mathrm{HT}_{\mathrm{IA}}$ receptors under psychosocial stress. J Neurosci 15:7132-7140.

Flügge G, Schniewind A, Fuchs E (1988) The corticosterone receptive system in the brain of Tupaia helangeri visualized by in vivo autoradiography. Exp Brain Res 72:417-424.

Flügge $G$, Jöhren O, Fuchs E (1992) ${ }^{3} \mathrm{H}$-rauwolscine binding sites in the brains of male tree shrews are related to social status. Brain Res 597:131-137.

Fuchs E, Flügge G (1995) Modulation of binding sites for corticotropinreleasing hormone by chronic psychosocial stress. Psychoneuroendocrinology 20:33-51.

Fuchs E, Schumacher M (1990) Psychosocial stress affects pineal function in the tree shrew (Tupaia belangeri). Physiol Behav 47:713-717.

Fuchs E, Jöhren O, Flügge G (1993) Psychosocial conflict in the tree shrew: effects on sympathoadrenal activity and blood pressure. Psychoneuroendocrinology 18:557-565.

Fuchs E, Uno H, Flügge G (1995) Chronic psychosocial stress induces morphological alterations in hippocampal pyramidal neurons of the tree shrew. Brain Res 673:275-282.

Gabbot PL, Somogyi J (1984) The "single" section Golgi impregnation procedurc: mcthodological description. J Ncurosci Methods 11:221-230.

Golumb J, Kluger A, de Leon MJ, Ferris SH, Convit A, Mittelman MS, Cohen J, Rusinek H, De Santi S, George AE (1994) Hippocampal formation size in normal human aging: a correlate of delayed secondary memory performance. Learn Memory 1:45-54.

Haydon P, McCobb D, Kater S (1985) Serotonin selectively inhibits growth cone motility and synaptogenesis of specific identified neurons. Science 226:561-564.

Jöhren O, Topp H, Sander G, Schöch G, Fuchs E (1991) Social stress in tree shrews increases the whole-body RNA degeneration rates. Naturwissenschaften 78:36-38.

Jöhren O, Flügge G, Fuchs E (1994) Hippocampal glucocorticoid receptor expression in the tree shrew: regulation by psychosocial conflict. Cell Mol Neurobiol 14:281-296.

Jolley ME (1981) Fluorescence polarization immunoassay for determination of therapeutic drug levels in human plasma. J Anal Toxicol 5:236-240.
Krugers HJ, Koolhaas JM, Bohus B, Korf J (1993) $\Lambda$ single social stressexperience alters glutamate receptor-binding in rat hippocampal CA3 area. Neurosci Lett 154:73-77.

Lowy MT, Gault L, Yamamoto BK (1993) Adrenalectomy attenuates stress-induced elevations in extracellular glutamate concentrations in the hippocampus. J Neurochem 61:1957-1960.

Luine V, Villegas M, Luine VN, McEwen BS (1993) Repeated stress causes reversible impairments of spatial memory performance. Behav Brain Res 639:167-170.

Magariños AM, McEwen BS (1995a) Stress-induced atrophy of apical dendrites of hippocampal CA3c neurons: comparison of stressors. Neuroscience $69: 83-88$.

Magariños AM, McEwen BS (1995b) Stress-induced atrophy of apical dendrites of hippocampal CA 3 c neurons: involvement of glucocorticoid secretion and excitatory amino acid receptors. Neuroscience 69:89-88.

Martin RD (1990) Primate origins and evolution. London: Chapman \& Hall.

McEwen BS, Sapolsky RM (1995) Stress and cognitive function. Curr Opin Neurobiol 5:205-216.

McEwen BS, Cameron H, Chao HM, Gould E, Magariños AM, Watanabe Y, Woolley CS (1993) Adrenal steroids and plasticity of hippocampal neurons: toward an understanding of underlying cellular and molecular mechanisms. Cell Mol Neurobiol 13:457-482.

Moghaddam B (1993) Stress preferentially increases extraneuronal levels of excitatory amino acids in the prefrontal cortex: comparison to hippocampus and basal ganglia. J Neurochem 60:1650-1657.

Nedergaard S, Enger T, Flatman J (1987) The modulation of excitatory amino acid responses by serotonin in the cat neocortex in vitro. Cell Mol Neurobiol 7:367-375.

Sapolsky RM (1992) Stress, the aging brain, and the mechanisms of neuron death. Cambridge: MIT.

Sloviter RS (1993) "Epileptic" brain damage in rats induced by sustained electrical stimulation of the perforant path. I. Acute electrophysiological and light microscopic studies. Brain Res Bull 10:675-697.

Squirre L (1983) The hippocampus and the neuropsychology of memory. In: Neurobiology of the hippocampus (Seifert W, ed), pp 491-511. London: Academic.

Starkman MN, Gebarski SS, Berent S, Schteingart D (1992) Hippocampal formation volume, memory dysfunction, and cortisol levels in patients with Cushing's Syndrome. Biol Psychiatry 32:756-765.

Taft WC, Clifton GL, Blair RE, Delorenzo RJ (1989) Phenytoin protects against ischemia-produced neuronal cell death. Brain Res 483:143-148.

Udenfriend S, Diekmann-Gerber L, Brink L, Spector S (1985) Scintillation proximity radioimmunoassay utilizing ${ }^{125}$ I-labeled ligands. Proc Natl Acad Sci USA 82:8672-8676.

Uno H, Eisele S, Sakai A, Shelton S, Baker E, DeJesus O, Holden J (1994) Neurotoxicity of glucocorticoid in the primate brain. Horm Behav Res 28:336-348.

Watanabe Y, Gould E, Cameron H, Daniels D, McEwen BS (1992a) Phenytoin prevents stress- and corticosterone-induced atrophy of CA3 pyramidal neurons. Hippocampus 2:431-436.

Watanabe Y, Gould E, Daniels D, Cameron H, McEwen BS (1992b) Tianeptine attenuates stress-induced morphological changes in the hippocampus. Eur J Pharmacol 588:341-345.

Watanabe Y, Gould E, McEwen BS (1992c) Stress induces atrophy of apical dendrites of hippocampal CA3 pyramidal neurons. Brain Res 588:341-345.

Woolley C, Gould E, McEwen BS (1990) Exposure to excess glucocorticoids alters dendritic morphology of adult hippocampal pyramidal neurons. Brain Res 531:225-231.

Yaari Y, Sclzer ME, Pincus JH (1986) Phenytoin: mechanisms of its anticonvulsant action. Ann Neurol 20:171-184. 